\title{
Strong Hydration Ability of Silk Fibroin Suppresses Formation and Recrystallization of Ice Crystals During \\ Cryopreservation
}

Qingrui Fan, ${ }^{\dagger a}$ Mengjia Dou, ${ }^{\dagger b, c, d}$ Junqiang Mao ${ }^{a}$, Yi Hou, ${ }^{b, c, e}$ Shuo Liu, ${ }^{a}$ Lishan Zhao, ${ }^{f}$ Jianyong Lv, ${ }^{f}$ Zhang Liu, ${ }^{a}$ Yilin Wang ${ }^{a}$, Wei Rao, *b, c, e Shenglin Jin, *a, f Jianjun Wang*a, e, $f$

a. Key Laboratory of Green Printing, Beijing National Laboratory for Molecular Science, Institute of Chemistry, Chinese Academy of Sciences, Beijing 100190 (China)

E-mail: shenglinjin@iccas.ac.cn

E-mail: wangj220@iccas.ac.cn

b. CAS Key Laboratory of Cryogenics, Technical Institute of Physics and Chemistry, Chinese Academy of Sciences, Beijing, 100190, China

E-mail: weirao@mail.ipc.ac.cn

c. Beijing Key Laboratory of Cryo-Biomedical Engineering, Beijing, 100190, China

d. School of Engineering Science, University of Chinese Academy of Sciences, Beijing 100049, China

e. School of Future Technology, University of Chinese Academy of Sciences, Beijing 100049, China

f. Songshan Lake Materials Laboratory, Dongguan, Guangdong 523808, P. R. China

$[+]$ These authors contributed equally to this work.

Supporting information for this article is given via a link at the end of the document. 


\section{Experimental Section}

1.1 Nanoliter Osmometer Experiments: The morphology of ice growth was measured through a custom-designed nanoliter osmometer with precision of $0.01{ }^{\circ} \mathrm{C}$. The procedure followed study reported elsewhere. ${ }^{1}$ Briefly, sub-microliter volume of the 20 $\mathrm{mg} \mathrm{mL} \mathrm{m}^{-1}$ Fib solution was injected into a temperature-controlled sample holder full of silicone oil using a microsyringe. Fib solution immerged in oil was quickly frozen, and then slowly warmed. Once a single ice crystal appeared, then keeping for about $15 \mathrm{~s}$ and the temperature was recorded as melting temperature $\left(\mathrm{T}_{\mathrm{m}}\right)$. Then the temperature was slowly decreased to a specific value $\left(T_{f}\right)$, at which ice starts to grow. Supercooling temperature $(\Delta T)$ is obtained by subtracting $T_{f}$ from $T_{m}$. This procedure was recorded by a high-speed camera (Phantom V7.3).

1.2 Spin-spin relaxation time and diffusion measurements: The spin-spin relaxation time $\left(T_{2}\right)$ is obtained through Niumag Bench-Top Pulsed NMI20-Analyst (Niumag Electric Corporation, Shanghai, China) at $25.0{ }^{\circ} \mathrm{C}$. The procedure followed study reported elsewhere. ${ }^{2}$ Herein, the employed solution volume is around $4 \mathrm{~mL}$. Besides, the diffusion measurements of water protons were carried out on a Bruker AVIII 500wb NMR spectrometer using the Carr-Purcell-Meiboom-Gill pulse sequence at $25.0^{\circ} \mathrm{C}$. A spacing of $1.2 \mathrm{~ms}$ between the $90^{\circ}$ and $180^{\circ}$ pulse was used, and a relaxation delay of five times of the spin-lattice relaxation time between consecutive scans was necessary to ensure full recovery of the magnetization between acquisitions. The SF is dissolved in $\mathrm{D}_{2} \mathrm{O}(99.98 \%)$ and the solution is filled into the 5-mm diameter NMR tubes.

1.3 In-situ Low-Temperature attenuated total reflection-infrared (ATR-IR): The variation of IR was measured on the Bruker 80 . The solution droplet $(100 \mu \mathrm{L})$ was dropped onto the Si prism precooled to $-60{ }^{\circ} \mathrm{C}$ from a height of $1.5 \mathrm{~m}$ to form polycrystalline ice. Then the temperature is raised to anneal the system $\left(-6{ }^{\circ} \mathrm{C}\right)$ at a rate of $5^{\circ} \mathrm{C}$ min $^{-1}$, seeing the Schematic S1.

1.4 Liposome Preparation: dimyristoyl phosphatidylcholine (DMPC, $10.0 \mathrm{mg}$ ) was dissolved in chloroform in a round-bottomed flask. The chloroform solvent was evaporated under the rotary evaporator to produce a thin lipid film. The film was subsequently dried overnight under a vacuum. The resulting lipid film was hydrated in 
aqueous solution. Single unilamellar vesicles were obtained using a mini-extruder set (Avanti Polar Lipids) and membranes of these vesicles were with $100 \mathrm{~nm}$ pore size, and obtaining $100 \mathrm{~mL}$. Liposomes were closed vesicles made up of phospholipid bilayers and enclosed an aqueous solution; hence, they were commonly used as cell membrane mimics.

1.5 Isothermal titration calorimetry (ITC): The calorimetric measurements were conducted on a Model TAM 2277-201 microcalorimetric system (Thermometric AB, Jarfalla, Sweden) with a $1 \mathrm{~mL}$ stainless steel sample cell at $25.00 \pm 0.01^{\circ} \mathrm{C}$. The sample cells were initially loaded with $750 \mu \mathrm{L}$ DMPC $(0.08 \mathrm{mM})$ solution. Then SF solution ( $85.0 \mathrm{mg} \mathrm{mL}^{-1}$, herein, the average molecular weight of amino acids can be assumed $85.0 \mathrm{~g} \mathrm{~mol}^{-1}$ for SF. ${ }^{3}$ Therefore, the molar concentration of amino acids is around 1.00 $\mathrm{mM}$ for $85.0 \mathrm{mg} \mathrm{mL}^{-1} \mathrm{SF}$ solution.) was consecutively injected into the stirred sample cell in portions of $10 \mu \mathrm{L}$ via a $500 \mu \mathrm{L}$ Hamilton syringe. This process was controlled by a 612 Thermometric Lund pump until the interaction progress completed. The system was stirred at $60 \mathrm{rpm}$ with a gold propeller. The curve was repeated at least twice with a deviation within $\pm 4 \%$. The dilution enthalpy of SF was subtracted from the corresponding observed enthalpy curve of SF with DMPC liposome. The binding parameters of SF and DMPC liposomes were obtained by fitting the enthalpy curves with the model of the two sets of binding sites provided in Origin scientific plotting software v9.0.

\subsection{ITC Analysis Process for the Model of Two Sets of Binding Sites:}

In the following equations,

$K_{a}=$ binding constant;

$\Delta H=$ the molar heat of SF binding;

$[\mathrm{X}]$ is the free concentration of SF;

$\mathrm{M}$ are the free concentration of DMPC Liposome;

$\Theta=$ fraction of sites occupied by SF;

$\mathrm{M}+\mathrm{X} \Leftrightarrow \mathrm{MX}_{1} \quad K_{a l}, \Delta H_{1}$

$\mathrm{MX}_{1}+\mathrm{X} \Leftrightarrow \mathrm{MX}_{2} \quad K_{a 2}, \Delta H_{2}$

The interaction process may be described in a simplified fashion using equation. 
$K_{a 1=} \frac{\Theta 1}{(1-\Theta)[\mathrm{X}]}$

$K_{a 2}=\frac{\Theta 2}{(1-\Theta 2)[\mathrm{X}]}$

This can be used in the Marquardt algorithm to obtain best values for the fitting parameters $\mathrm{K}_{\mathrm{a} 1}$, and $\mathrm{K}_{\mathrm{a} 2}$. More information about the analysis for the model of two sets of independent sites can befound in ITC Data Analysis in Origin ${ }^{\circledR}$ Tutorial Guide Version 7.0

1.7 Electron spin resonance (ESR) Spectroscopy: DMPC (0.013 mmol) was dissolved in chloroform, then $1 \times 10^{-4} \mathrm{mmol} 16$-DSA were added, respectively, to prepare the corresponding spin-labeled liposomes. The chloroform solvent was evaporated under a rotary evaporator to produce a thin lipid film. The film was subsequently dried under a vacuum overnight. The resulting lipid film was hydrated in aqueous solution, and single unilamellar vesicles were obtained using a mini-extruder set (Avanti Polar Lipids) and membranes with a $100 \mathrm{~nm}$ pore size. The various concentration of SF and Fic were suspended liposomes solution and stored at liquid nitrogen. After $24 \mathrm{~h}$, the solution was thawed in a $37^{\circ} \mathrm{C}$ water bath. The solution was then transferred to an ESR quartz flat cell equipped with a screw knob (ESLC12; JEOL, Tokyo, Japan). The flat cell was placed in the cavity of the spectrometer, and ESR spectra were recorded on a JEOL JESFA100 ESR spectrometer, using the following parameters: sweeping field, $333 \pm$ $10 \mathrm{mT}$; microwave power, $10 \mathrm{~mW}$; modulation width, $0.02 \mathrm{mT}$; sweep time, 2 mins; total sweep, 10; time constant, $0.03 \mathrm{~s}$; and amplitude, 1000.

1.8 Red blood cells (RBCs) preparation: Sheep RBCs (defibrinated, packed cell volume of $20 \%$, stored in Alsever's solution) were purchased on-demand from Beijing Abcam Technology Ltd. They were centrifuged at $1000 \mathrm{rpm}$ for $5 \mathrm{mins}$ and the top layer (containing any residual plasma and its constituents) was removed and replaced with an equal volume of PBS. When not in use, cells were stored in this form at $4{ }^{\circ} \mathrm{C}$ for a maximum of 7 days.

1.9 Cytotoxicity assay: SF dissolved in PBS solution with the desired concentrations. Then a $50 \mu \mathrm{L}$ sample of prepared RBCs (in triplicate) was transferred to $50 \mu \mathrm{L}$ of SFPBS solution with a series of concentrations in $2 \mathrm{~mL}$ centrifuge tube and the samples 
were vortexed gently, giving a final pack cell volume of $10 \%$ and final SF concentrations of $15.0,30.0,50.0$ and $75.0 \mathrm{mg} \mathrm{mL}^{-1}$. Blank contrast samples were prepared by the addition of $50 \mu \mathrm{L}$ prepared RBCs to $50 \mu \mathrm{L}$ PBS. Each sample was preserved at $4{ }^{\circ} \mathrm{C}$ for 6 days before RBCs hemolysis measurement.

1.10 RBCs cryopreservation: The RBCs cryopreservation experiments were carried out by referring to the reported paper. ${ }^{4}$ Firstly, SF was dispersed in PBS solution with the desired concentrations. Then a $60 \mu \mathrm{L}$ aliquot of prepared RBCs (in quintuplicate) was added to $60 \mu \mathrm{L}$ of SF-PBS solutions with a series of concentrations in $1.5 \mathrm{~mL}$ cryovials and the samples were vortexed gently, giving a final pack cell volume of $10 \%$ and final cryoprotectants concentrations of 15.0, 30.0, 50.0 and $75.0 \mathrm{mg} \mathrm{mL}^{-1}$ for SF. Each sample was then plunged into liquid nitrogen for $5 \mathrm{~h}$. Subsequently, samples were allowed to thaw at $23^{\circ} \mathrm{C}$ (air) for 30 mins before cell recoveries were measured.

1.11 Measurement of RBCs hemolysis and cell recovery: $:^{4,5}$ A $60 \mu \mathrm{L}$ aliquot of the RBCs suspension to be tested was added to $600 \mu \mathrm{L}$ PBS and centrifuged (1000 rpm, 5 mins, $4{ }^{\circ} \mathrm{C}$ ) to remove intact cells. Then, $200 \mu \mathrm{L}$ of the supernatant was added to 2.5 $\mathrm{mL}$ of PBS. An absorbance measurement at $415 \mathrm{~nm}$, where is the maximum absorption peak of hemoglobin, was recorded by the UV-Vis spectrophotometer (Shimadzu UV2550 ) to assess the extent of hemolysis and cell recovery. $100 \%$ hemolysis samples were prepared by osmotic shock through the addition of $500 \mu \mathrm{L} \mathrm{H}_{2} \mathrm{O}$ to a $500 \mu \mathrm{L}$ prepared RBCs that were vortexed vigorously and cryopreserved with an absence of cryoprotectant and thawed slowly. Control ( $0 \%$ hemolysis) samples were prepared by the addition of $500 \mu \mathrm{L}$ PBS to a $500 \mu \mathrm{L}$ prepared RBCs and left untreated at $23{ }^{\circ} \mathrm{C}$ for 60 mins. Cell recovery was calculated by subtracting the attained hemolysis (\%) from $100(\%)$ and giving a figure for cell recovery $(\%){ }^{6}$ 


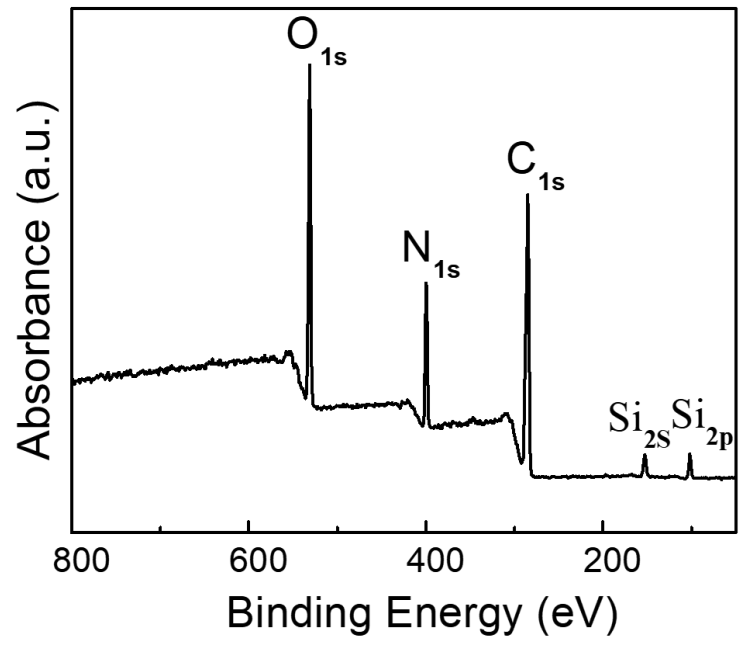

Figure S1. XPS data of the $\mathrm{SiO}_{2}$ surface coated by the SF. 
(a)

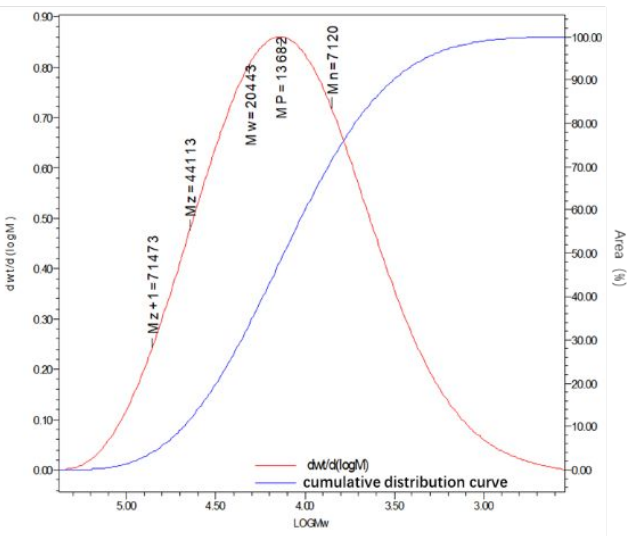

(b)

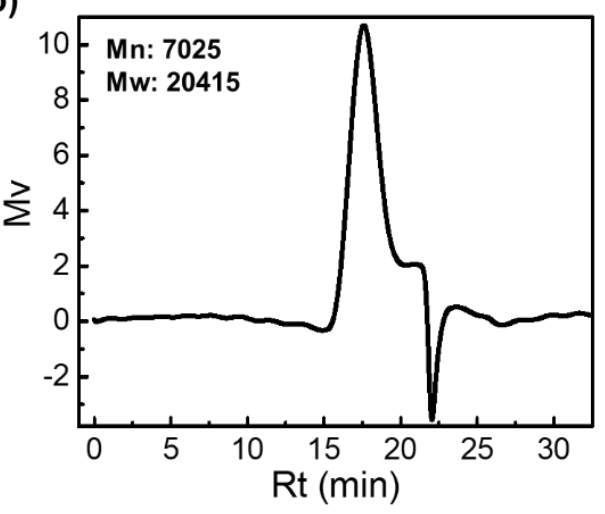

Figure S2. The molecular weight distribution and cumulative distribution curve.

Table S1 the molecular weight of SF via GPC

\begin{tabular}{|r|r|r|r|r|r|r|r|}
\hline $\begin{array}{c}\text { Mn } \\
\text { (Daltons) }\end{array}$ & $\begin{array}{c}\text { Mw } \\
\text { (Daltons) }\end{array}$ & $\begin{array}{c}\text { MP } \\
\text { (Daltons) }\end{array}$ & $\begin{array}{c}\text { Mz } \\
\text { (Daltons) }\end{array}$ & $\begin{array}{c}\text { Mz+1 } \\
\text { (Daltons) }\end{array}$ & polydisersity & Mz/ Mw & Mz+1/ Mw \\
\hline 7025 & 20415 & 13683 & 44113 & 71473 & 2.91 & 2.16 & 3.50 \\
\hline
\end{tabular}




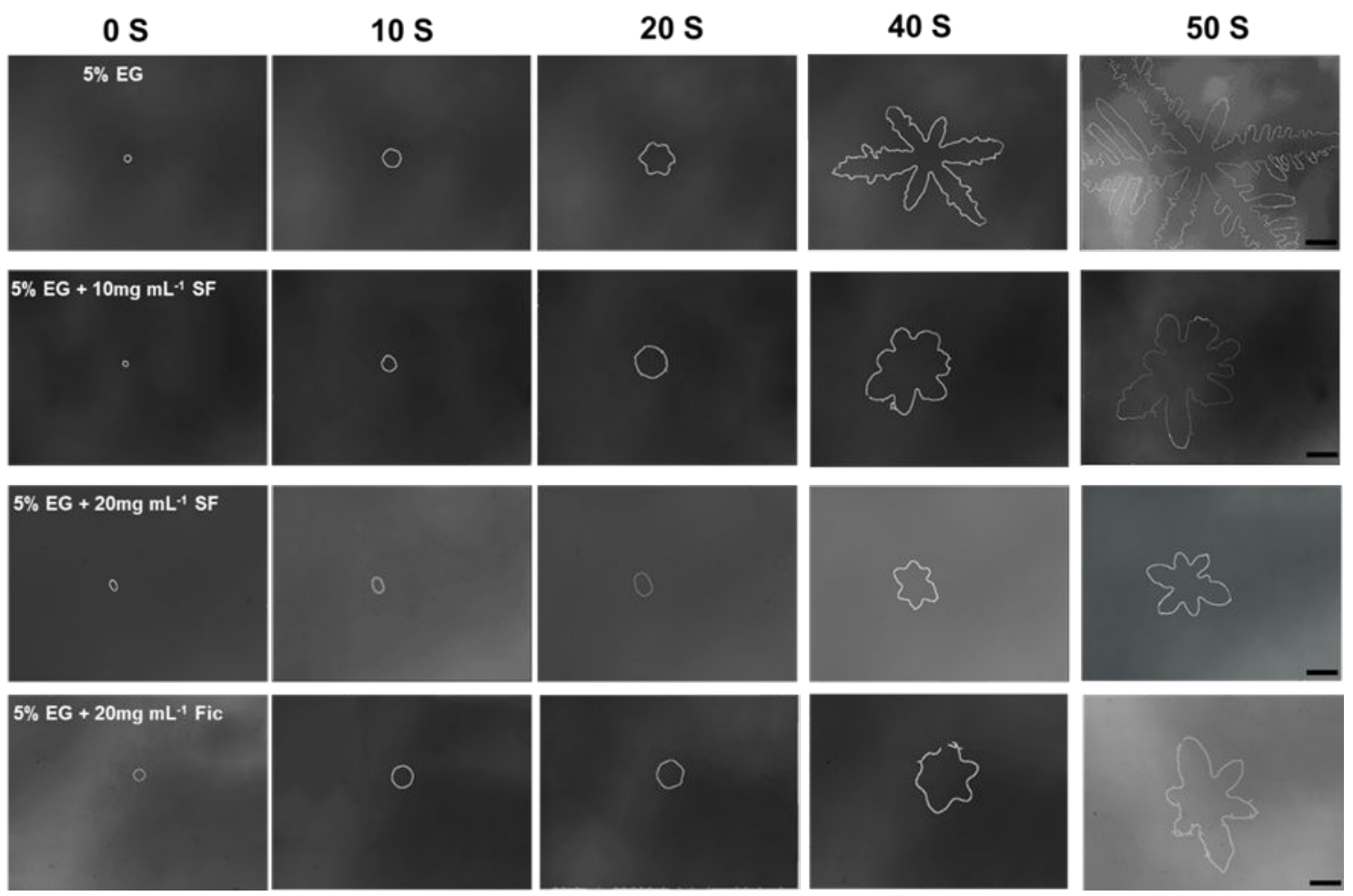

Figure S3. Optical microscopy images of growth of single ice crystal in 5\% EG solutions with and without CPAs at $0 \mathrm{~s}$ to $50 \mathrm{~s}$ under supercooling temperature of $\left(\Delta T_{1}\right)$ of $0.5^{\circ} \mathrm{C}$. The scale bar is $100 \mu \mathrm{m}$. 


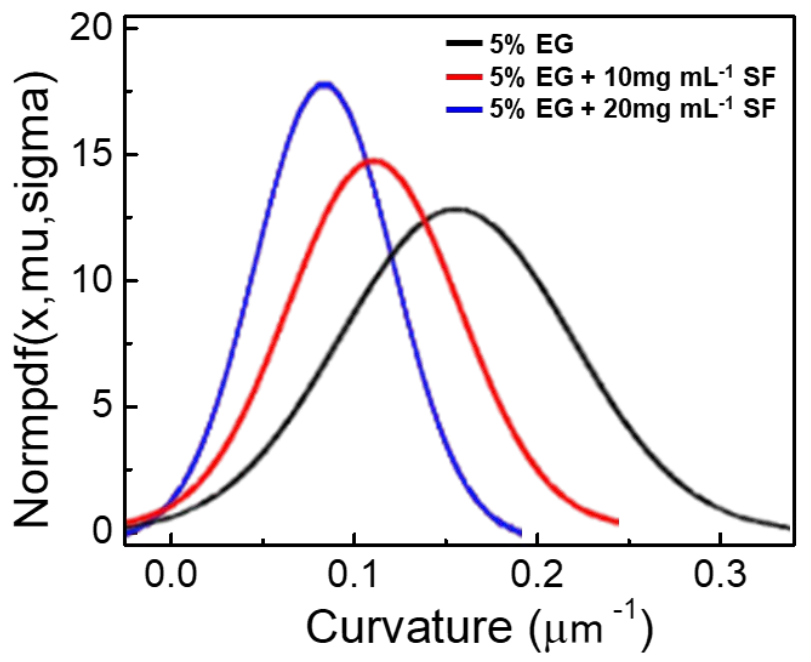

Figure S4. The curvature distribution of ice crystal under various SF concentration. 

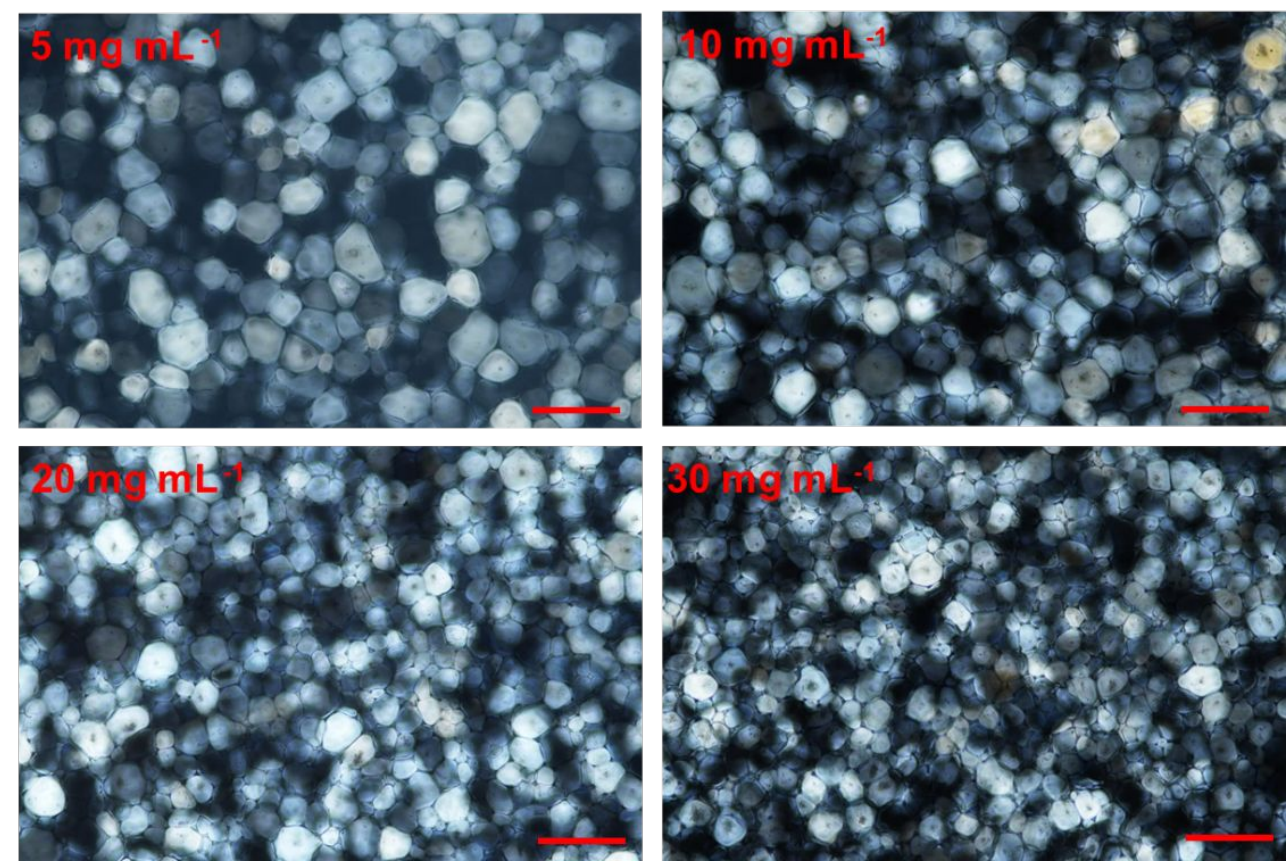

Figure S5. Optical microscopic images display ice crystals recrystallized in PBS with and without SF after annealing at $-6.0^{\circ} \mathrm{C}$ for $30 \mathrm{~min}$. Scale bar is $200 \mu \mathrm{m}$. 

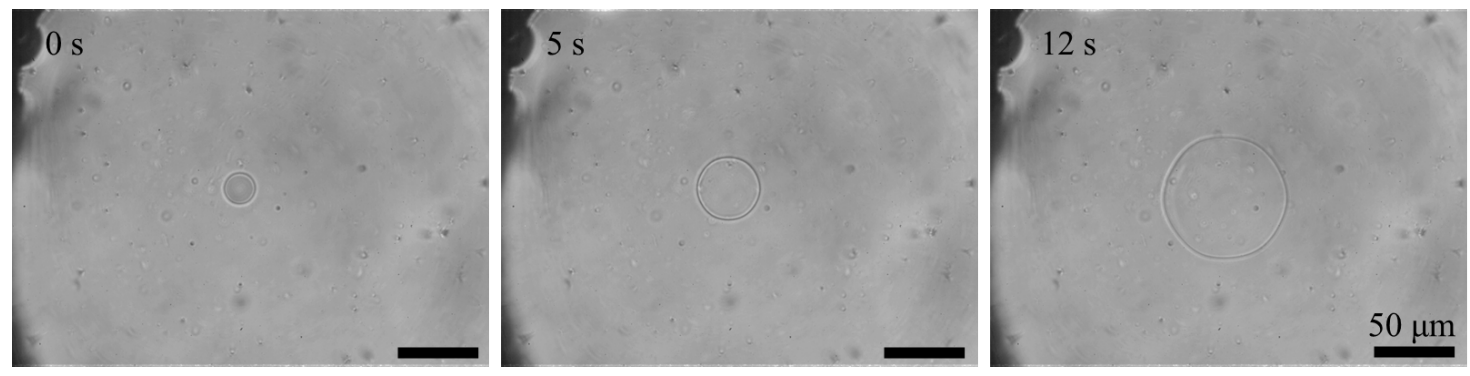

Figure S6. Growth processes of single ice crystals in SF $\left(20 \mathrm{mg} \mathrm{mL}^{-1}\right)$ aqueous solution, $T=-0.3{ }^{\circ} \mathrm{C}$. Scale bar: $50 \mu \mathrm{m}$. 
Table S2. The values of $T_{f}, T_{r}, T_{m}$, and $T_{m}-T_{r}\left(\Delta T_{2}\right)$ obtained from DSC.

\begin{tabular}{|l|c|c|c|c|}
\hline & ES40 & $\begin{array}{c}\text { ES40+ } \\
10.0 \mathrm{mg} \mathrm{mL}^{-1} \mathrm{Fic}\end{array}$ & $\begin{array}{c}\text { ES40+ } \\
5.0 \mathrm{mg} \mathrm{mL}^{-1} \mathrm{Fib}\end{array}$ & $\begin{array}{c}\text { ES40+ } \\
10.0 \mathrm{mg} \mathrm{mL}^{-1} \mathrm{Fib}\end{array}$ \\
\hline $\mathrm{T}_{\mathrm{f}}\left({ }^{\circ} \mathrm{C}\right)$ & -85.4 & -74.4 & & \\
\hline $\mathrm{T}_{\mathrm{r}}\left({ }^{\circ} \mathrm{C}\right)$ & -100.3 & -98.4 & -82.4 & -62.4 \\
\hline $\mathrm{T}_{\mathrm{m}}\left({ }^{\circ} \mathrm{C}\right)$ & -31.3 & -32.4 & -37.1 & -40.9 \\
\hline$\Delta \mathrm{T}_{2}\left({ }^{\circ} \mathrm{C}\right)$ & 69.0 & 68.0 & 45.3 & 21.5 \\
\hline
\end{tabular}


Table S3 The integral area of DSC result from different solution.

\begin{tabular}{|l|l|l|l|l|}
\hline & ES40 & $\begin{array}{l}\text { ES40+ } \\
10.0 \quad \mathrm{mg} \\
\mathrm{ml}^{-1} \mathrm{Fic}\end{array}$ & $\begin{array}{l}\text { ES40+ } \\
5.0 \quad \mathrm{mg} \\
\mathrm{ml}^{-1} \mathrm{SF}\end{array}$ & $\begin{array}{l}\text { ES40+ } \\
10.0 \quad \mathrm{mg} \\
\mathrm{ml}^{-1} \mathrm{SF}\end{array}$ \\
\hline $\begin{array}{l}\text { Exothermic } \\
\text { enthalpy } \\
\Delta H_{f}\left(\mathrm{~J} \mathrm{~g}^{-1}\right)\end{array}$ & -3.17 & -23.14 & -30.57 & -10.92 \\
\hline $\begin{array}{l}\text { Exothermic } \\
\text { enthalpy } \\
\Delta H_{r}\left(\mathrm{~J} \mathrm{~g}^{-1}\right)\end{array}$ & -33.54 & -11.1 & 27.33 & 7.28 \\
\hline $\begin{array}{l}\text { Endothermic } \\
\text { enthalpy } \\
\Delta H_{m}\left(\mathrm{~J} \mathrm{~g}^{-1}\right)\end{array}$ & 39.18 & 32.94 & & \\
\hline
\end{tabular}



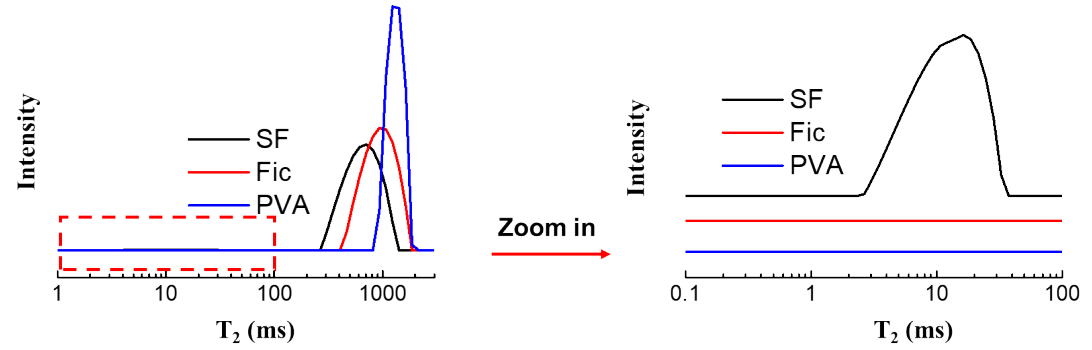

Figure S7. Relaxation time $\left(\mathrm{T}_{2}\right)$ inversion spectra (signal intensity as a function of corresponding $\mathrm{T}_{2}$ ) of the water in ES40 with SF, Fic, and poly (vinyl alcohol) (PVA) solution at $25{ }^{\circ} \mathrm{C}$. The concentrations of SF, Fic, and PVA are $10.0 \mathrm{mg} \mathrm{mL}^{-1}$. 


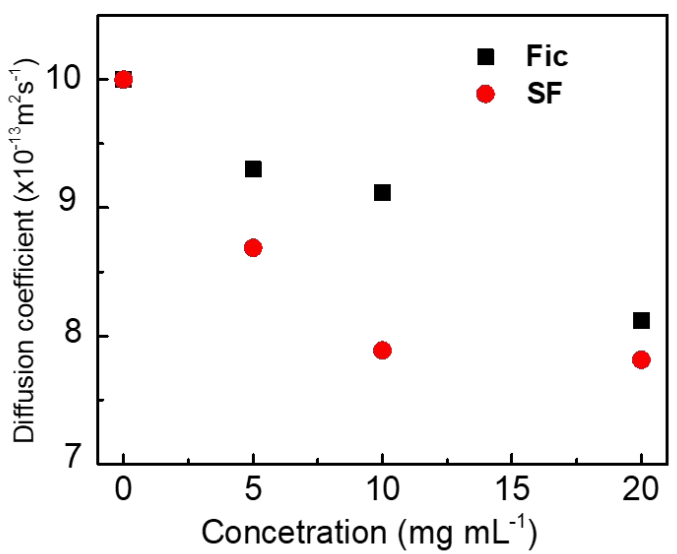

Figure S8. Diffusion coefficients of SF and Fic as a function of concentrations in $\mathrm{D}_{2} \mathrm{O}$ at $25^{\circ} \mathrm{C}$. 


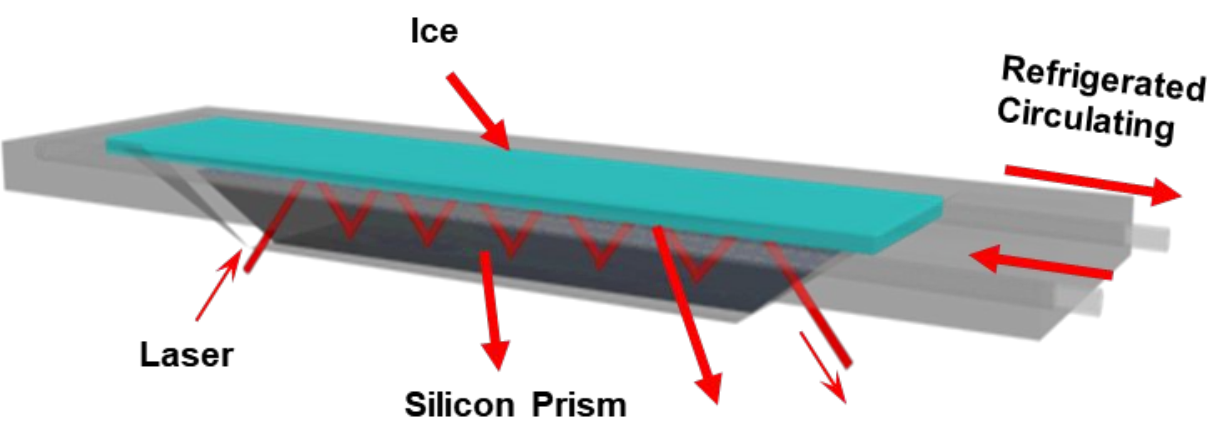

Schematic S1. A schematic illustrating in-situ low temperature attenuated total reflection-infrared. 


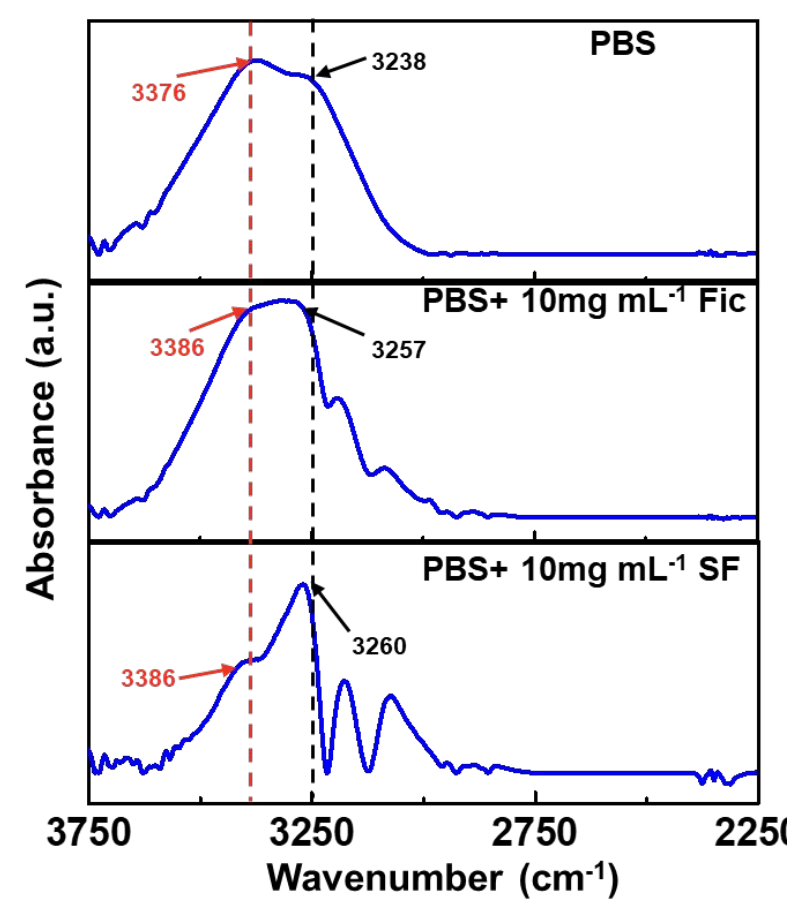

Figure S9. The ice crystals evolution after annealing 60 mins under different solution through in-situ low temperature attenuated total reflection-infrared (ATR-IR).

The spectral profile of the $\mathrm{OH}$ stretching band could be described by the superposition of several Gaussian components, which could reflect the changes of the hydrogen bond of the water-ice system ${ }^{7,8}$. Detailed information regarding the molecular configuration of water could be found from analysis of peak of lower frequency $\left(\sim 3250 \mathrm{~cm}^{-1}\right)$ and higher frequency $\left(\sim 3400 \mathrm{~cm}^{-1}\right)$ corresponding to the stretching vibrations of completely self-associated "icelike" water (H-bond coordination number closing to four) and free water (H-bond coordination of water molecules closing to dimers or trimers), respectively. As the annealing, the spectroscopy displayed obvious difference from a different solution. More specially, the intensity of free water peak was larger than the intensity of "ice" water peak or almost same with intensity of "ice" water peak for the PBS and PBS+Fic solution, while the intensity of the free water peak is far less than intensity of "ice" water peak for PBS+SF solution. The results of ATR-IR demonstrated that the "icelike" water could be kept stable as adding SF during the ice recrystallization, and the content of free water also obliviously decreased as adding the SF. 


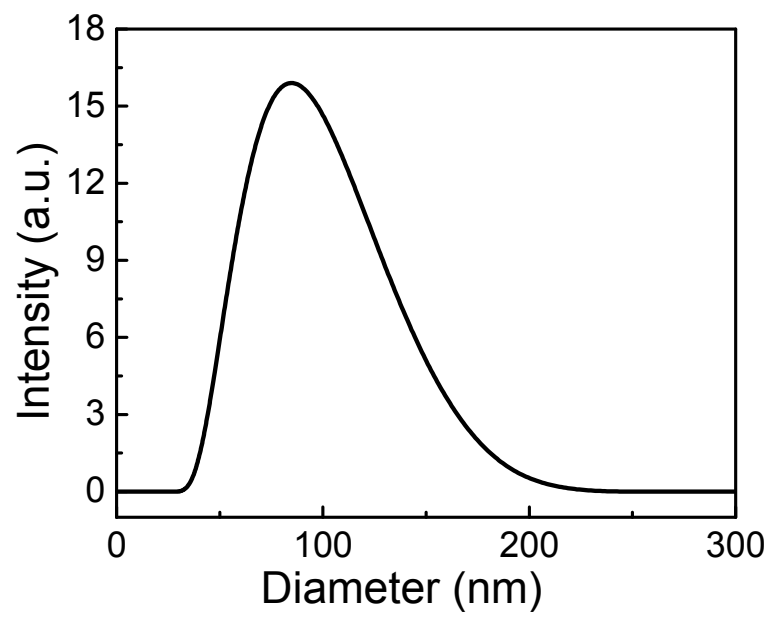

Figure S10. The size distribution of liposome, which the size was around $100 \mathrm{~nm}$. 


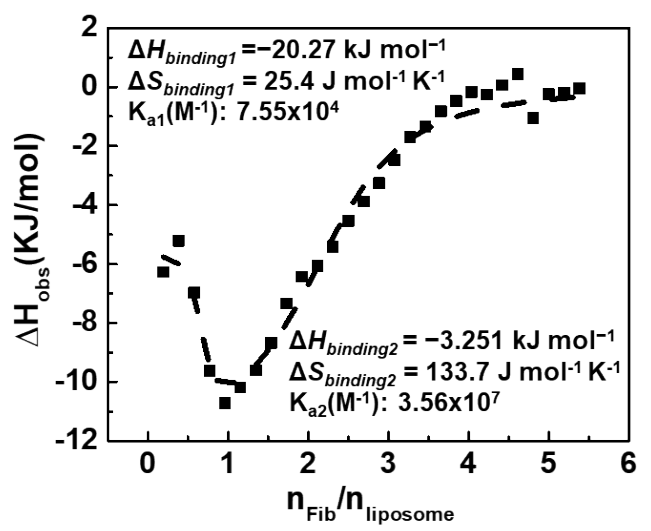

Figure S11. The observed enthalpy changes $\left(\Delta H_{\mathrm{obs}}\right)$ against the molar ratio of SF/DMPC liposomes by titrating SF into DMPC liposomes' PBS solution. $\left(\Delta H_{\text {obs }}\right.$ values are expressed in terms of $\mathrm{kJ} \mathrm{mol}^{-1}, K_{a 1}$ and $K_{a 2}$ are the stepwise binding constants obtained by fitting the enthalpy curves with the model of the two sets of binding sites (SI).

As the uncontrolled ice growth and accompanying osmotic shock are viewed as the major causes responsible for damaging the structure integrity of the cell membranes during CP. Therefore, the liposome assembled from dimyristoylphosphatidylcholine (DMPC) as phospholipid bilayer was used as the prototype of cell membranes (Figure S11) to investigate the effect of SF on the stability of cell membranes by isothermal titration calorimetry (ITC). The PBS solution of SF was titrated into the sample cell initially containing DMPC PBS solution only, and the final enthalpy values as a function of the molar ratio of SF/DMPC was obtained. As shown in Figure 3a, the observed enthalpy change $\left(\Delta H_{o b s}\right)$ sharply increased as the increasing of the molar ratio of SF/DMPC (i.e., $\mathrm{n}_{\mathrm{SF}} / \mathrm{n}_{\text {liposome}}$ ) to 1.0. As further addition of SF, $\Delta H_{\mathrm{obs}}$ stars to decrease and finally returned to zero (please see ITC analysis in SI). ITC results suggested that the interaction between DMPC and SF involved two processes. Thus, the binding parameters of association constant $\left(K_{a}\right)$ and enthalpy $\left(\Delta H_{\text {binding }}\right)$ were obtained by fitting the ITC curves with the model of the two binding-site sets, including enthalpy favoured and entropy dominated process, respectively. ${ }^{9}$ That is, SF as binding enthalpy $\Delta H_{\text {binding } 1}$ $\left(-20.27 \mathrm{~kJ} \mathrm{~mol}^{-1}\right)$ is obviously less than $\Delta H_{\text {binding } 2}\left(-3.251 \mathrm{~kJ} \mathrm{~mol}^{-1}\right)$, implying that the 
first process is an enthalpy favoured process caused by the electrostatic interaction between the polar head of liposome and SF. ${ }^{9}$ Upon further addition of the SF, the binding entropy increased from $25.4 \mathrm{~J} \cdot \mathrm{mol}^{-1} \mathrm{~K}^{-1}\left(\Delta S_{\text {bindingl }}\right)$ to $133.7 \mathrm{~J} \cdot \mathrm{mol}^{-1} \mathrm{~K}^{-}$ ${ }^{1}\left(\Delta S_{\text {binding } 2}\right)$, indicating the hydrophobic interactions dominated the second process. ${ }^{9}$ Moreover, the $K_{a 2}\left(3.56 \times 10^{7} \mathrm{M}^{-1}\right)$ was almost three orders of magnitude larger than $K_{a l}\left(7.55 \times 10^{4} \mathrm{M}^{-1}\right)$, suggesting that hydrophobic interaction is dominated between the SF and the liposome. 
(a)

(i)

(ii)

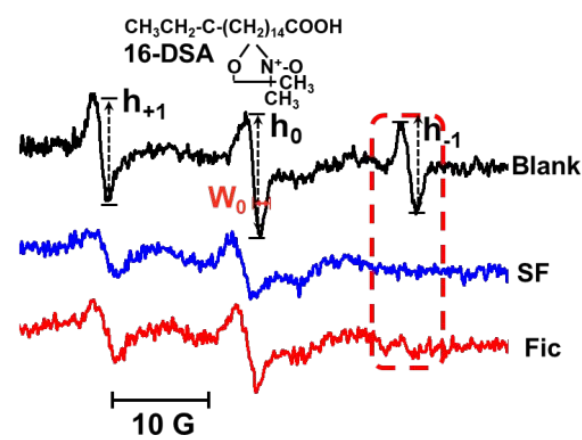

(b)

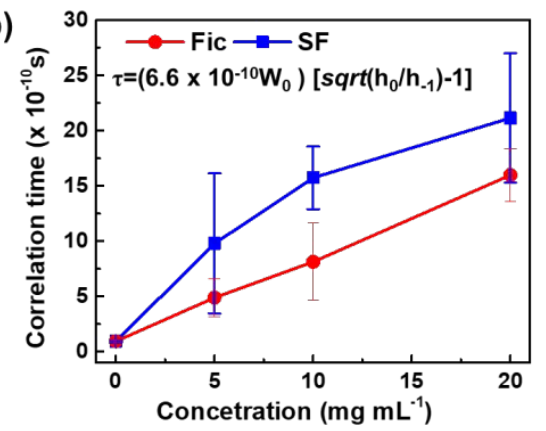

(c)

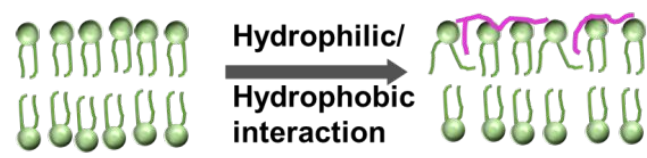

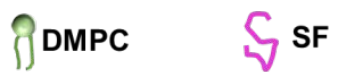

Figure S12 (a) Electron spin resonance (ESR) spectra of 16-doxyl stearic acid (16DSA, 1.0 moL \%) titrate into unilamellar dispersions of DMPC' PBS solution (pH 7.4) with (i) without any CPAs (ii) $10.0 \mathrm{mg} \mathrm{mL}^{-1}$ Fic and (iii) $10.0 \mathrm{mg} \mathrm{mL}^{-1} \mathrm{SF}$, where $\mathrm{h}_{0} / \mathrm{h}$. ${ }_{1} / h_{+1}$ is the ratio of the peak intensity of the central and high field lines, and $\mathrm{W}_{0}$ is the peak-to-peak width of the central line. (b) The quantitative assessment of the motional rate of DMPC $\left(\tau_{\mathrm{c}}\right)$ as a function of CPAs concentration, inset is the formula of $\tau_{\mathrm{c}}$. (c) The schematic illustration of the proposed interaction between the DMPC liposomes and SF.

The hydrophobic interaction between SF and DMPC was further examined by the electron spin resonance (ESR) spectroscopy. ${ }^{10}$ 16-Doxy-stearic acid (16-DSA), (i.e., a spin-labelled stearate with the nitroxide group at carbon-16 widely used for the determination of hydrophobic interaction), was used to introduce an unpaired electron to the lipid core region of DMPC, and showing three peaks of $h_{+1}, h$ and $h_{-1}$ in the ESR spectrum (Figure S12a i). ${ }^{10}$ With the addition of the $20.0 \mathrm{mg} \mathrm{mL}^{-1} \mathrm{SF}$ into the DMPC, the signal of $h_{-1}$ was disappeared, suggesting quenching of the free radicals, that is, the interaction between SF and DMPC (Figure S12a ii), and this interaction between SF and DMPC is stronger than that of Fic and MDPC (Figure S12a iii). Furthermore, the correlation time $\left(\tau_{c}\right)$, representing the motional rate of DMPC, was increased 10 times 
(from $2 \times 10^{-10} \mathrm{~s}$ to $2 \times 10^{-9} \mathrm{~s}$ ) upon addition of SF (Figure S12b). which further implies that the interaction of SF with DMPC slows down the motion of DMPC. ${ }^{10,11-13} \mathrm{~A}$ proposed interaction between SF and cell membranes was schematically illustrated in Figure S12c, the SF binds to the polar head of liposomes through electrostatic interaction, and then penetrates into the hydrophobic core of the membrane through hydrophobic interaction. These results reveal that the interaction of SF with membranes (DMPC) possibly help to stabilize the integrity of cell membrane and protect the cell membrane from cryoinjury, resulting from ice recrystallization and osmotic effect etc. 


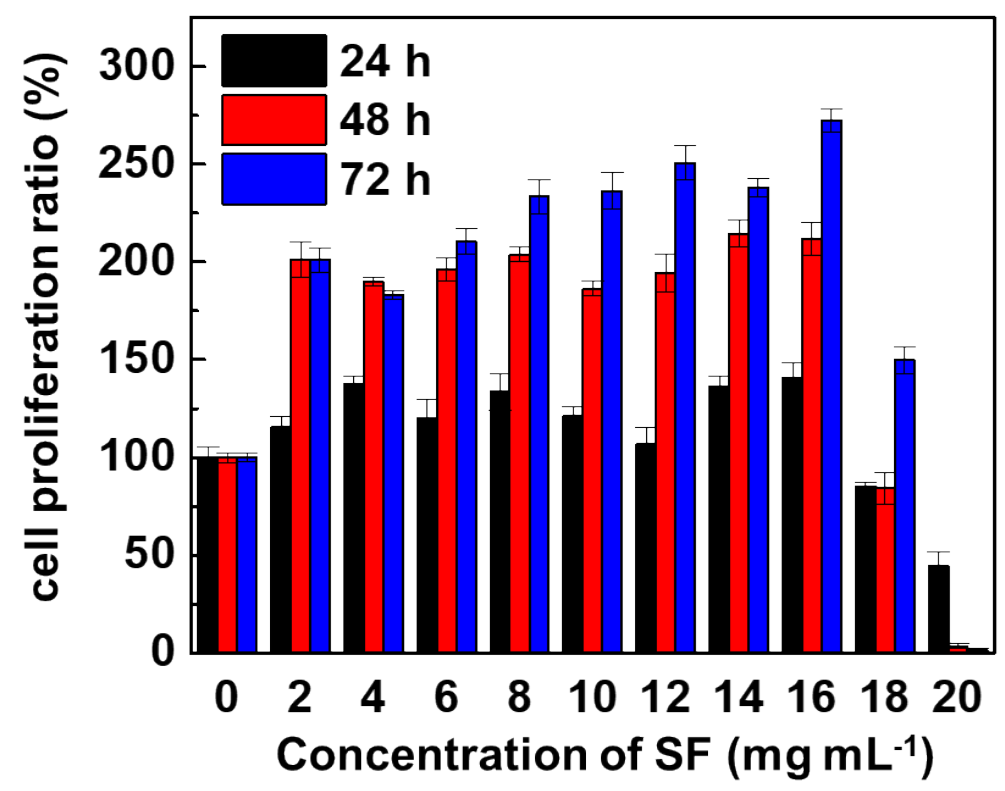

Figure S13. The cytocompatibility of SF on hBMSCs. 
Table S4. The corresponding primers of stem and reference genes used in RT-PCR studies

\begin{tabular}{lll}
\hline Gene & Primer & \\
\hline PPAR $\gamma$ & Sense primer & 5'-TCT CTC CGT AAT GGA AGA CC-3' \\
& Anti-sense primer & 5'-GCA TTA TGA GAC ATC CCC AC-3' \\
Collagen type I & Sense primer & 5'-GGG CAA GAC AGT GAT TGA ATA CA-3' \\
& Anti-sense primer & 5'-GGA TGG AGG GAG TTT ACA GGA A-3' \\
Sox9 & Sense primer & 5'-GCA GAG ACT GAA GAC CCT ACA CAG A-3' \\
& Anti-sense primer & 5'-GAG GCA ACT TCA CGC TGC AA-3' \\
GAPDH & Sense primer & 5'-GCA AGA GCA CAA AGA GAA GAG-3' \\
& Anti-sense primer & 5'-AAG GGG TCT ACA TGG CAA CT-3' \\
\hline
\end{tabular}




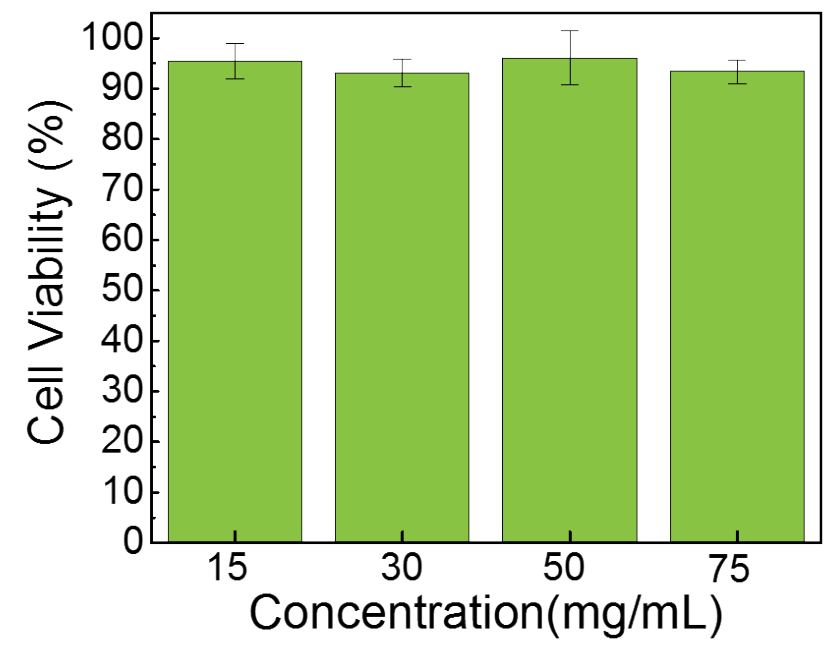

Figure S14. Evaluated the cytotoxicity of SF by measuring the viable counts of RBCs. RBCs were added to the PBS solution in the absence (cell viability $\%=100 \pm$ $4 \%$ ) or presence of the SF and incubated at $4{ }^{\circ} \mathrm{C}$ for 2 days. The results demonstrated that $\mathrm{SF}$ showed no obvious cytotoxicity to sheep RBCs at the concentration up to 75.0 $\mathrm{mg} \mathrm{mL} \mathrm{m}^{-1}$. 


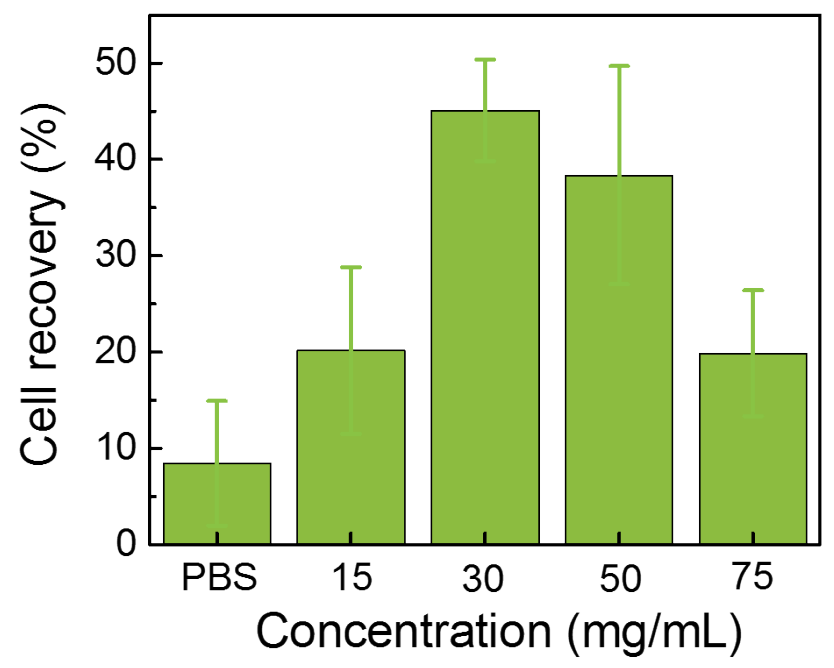

Figure S15. The recovery of sheep RBCs cryopreserved in SF-PBS solutions with different concentrations. The PBS dispersion was used as negative controls. 
1. Geng, H.; Liu, X.; Shi, G.; Bai, G.; Ma, J.; Chen, J.; Wu, Z.; Song, Y.; Fang, H.;

Wang, J., Graphene Oxide Restricts Growth and Recrystallization of Ice Crystals. Angew. Chem. Int. Ed. Engl. 2017, 56, (4), 997-1001.

2. Wu, S.; He, Z.; Zang, J.; Jin, S.; Wang, Z.; Wang, J.; Yao, Y.; Wang, J., Heterogeneous ice nucleation correlates with bulk-like interfacial water. $S c i . A d v .2019$, $5,(4)$, eaat9825.

3. Wang, C.; Xia, K.; Zhang, Y.; Kaplan, D. L., Silk-Based Advanced Materials for Soft Electronics. Acc. Chem. Res. 2019, 52, (10), 2916-2927.

4. Bai, G.; Song, Z.; Geng, H.; Gao, D.; Liu, K.; Wu, S.; Rao, W.; Guo, L.; Wang, J., Oxidized Quasi-Carbon Nitride Quantum Dots Inhibit Ice Growth. Adv. Mater. 2017, 29, (28), 1606843-1606850.

5. Deller, R. C.; Vatish, M.; Mitchell, D. A.; Gibson, M. I., Synthetic polymers enable non-vitreous cellular cryopreservation by reducing ice crystal growth during thawing. Nat. Commun. 2014, 5, 3244.

6. Dou, M.; Lu, C.; Sun, Z.; Rao, W., Natural cryoprotectants combinations of 1proline and trehalose for red blood cells cryopreservation. Cryobiology 2019, 91, 2329.

7. Asay, D. B.; Kim, S. H., Evolution of the adsorbed water layer structure on silicon oxide at room temperature. J. Phys. Chem. B 2005, 109, (35), 16760-16763.

8. Brubach, J. B.; Mermet, A.; Filabozzi, A.; Gerschel, A.; Roy, P., Signatures of the hydrogen bonding in the infrared bands of water. J. Chem. Phys. 2005, 122, (18), 184509. 
9. Zhou, C.; Wang, F.; Chen, H.; Li, M.; Qiao, F.; Liu, Z.; Hou, Y.; Wu, C.; Fan, Y.; Liu, L.; Wang, S.; Wang, Y., Selective Antimicrobial Activities and Action Mechanism of Micelles Self-Assembled by Cationic Oligomeric Surfactants. ACS Appl. Mater. Interfaces 2016, 8, (6), 4242-9.

10. Rajan, R.; Hayashi, F.; Nagashima, T.; Matsumura, K., Toward a Molecular Understanding of the Mechanism of Cryopreservation by Polyampholytes: Cell Membrane Interactions and Hydrophobicity. Biomacromolecules 2016, 17, (5), 188293.

11. Lai, C. S.; Schutzbach, J. S., Localization of dolichols in phospholipid membranes. An ESR spin label study. FEBS Lett. 1986, 203, (2), 153-6.

12. Wassall, S. R.; Phelps, T. M.; Albrecht, M. R.; Langsford, C. A.; Stillwell, W., Electron spin resonance study of the interactions of retinoids with a phospholipid model membrane. Biochim. Biophys. Acta. 1988, 939, (2), 393-402.

13. Yin, J. J.; Smith, M. J.; Eppley, R. M.; Page, S. W.; Sphon, J. A., Effects of fumonisin B1 on lipid peroxidation in membranes. Biochim. Biophys. Acta. 1998, 1371, (1), 134-42. 